\title{
CONSUMER CONFUSION WITH LEVELS OF VEHICLE AUTOMATION
}

\author{
Bobbie Seppelt ${ }^{1}$, Bryan Reimer ${ }^{1}$, Luca Russo ${ }^{1}$, Bruce Mehler $^{1}$, Jake Fisher ${ }^{2}$, David Friedman ${ }^{2}$ \\ ${ }^{1}$ MIT AgeLab \& N.E. Univ. Transportation Center, Cambridge, MA, USA \\ ${ }^{2}$ Consumer Reports, Yonkers, NY, USA \\ Email: bseppelt@mit.edu
}

\begin{abstract}
Summary: A consumer-facing automation taxonomy is proposed to address emergent issues of consumer confusion related to automation types and associated role responsibility. A set of surveys were fielded to help understand the extent to which consumers were able to accurately interpret a proposed consumer-facing taxonomy relative to the 6-level SAE J3016 taxonomy. Results show a mixed benefit of the proposed set over the J3016 set. For both term types and definitions, consumers were best able to differentiate the extremes of automation types, leading to the question of whether or not it may be beneficial to provide a simplified representation to communicate functionality. A binary framing ("driving" vs. "riding") in place of a 6-level taxonomy is proposed to ensure consumer understanding.
\end{abstract}

\section{INTRODUCTION}

A key human-related issue within vehicle automation concerns the degree of human engagement required to maintain safe control, either as an operator, monitor, supervisor, or passenger. To act appropriately in these roles, the human must have a clear understanding of his/her driving responsibilities at any given moment of time. These responsibilities change based on the type of automation engaged (SAE J3016, 2018).

Recent research indicates that consumers are often confused about the capabilities of deployed forms of vehicle automation due to role confusion, misattributing greater role responsibility to automation based on technology naming alone (Abraham et al., 2017). Perceptions of automated system capabilities are further inflated based on media reports and individual tendency to adopt new forms of technology (Lee et al., 2018).

Implications of automation's introduction to human responsibility, including oversimplified function allocation of the primary driving subtasks to human or technology, are well-documented (e.g., Casner et al., 2014; Lee, 2018; Wickens \& Kessel, 1981; Woods, 2016). Consumer confusion around important but complex descriptions of six levels of automation, written by engineers for engineers, further complicates general interpretation (SAE J3016, 2018).

A proposal for a consumer-facing automation taxonomy is shown in Table 1. In this framing, a short definition and primary purpose is defined for each automation type, along with a designation of "who" is primarily responsible for safety, and if the human is free to engage in non-driving related activities. The hierarchy of this taxonomy presents a simplified designation of "driving" and "riding". This framing is proposed to communicate the key automation type classifier of "who" (human or automation) is responsible for safety. 
Table 1. Consumer-facing automation type taxonomy

\begin{tabular}{|c|c|c|c|c|c|}
\hline $\begin{array}{l}\text { Human's } \\
\text { Role }\end{array}$ & $\begin{array}{l}\text { Automation } \\
\text { Type }\end{array}$ & Definition & $\begin{array}{l}\text { Primary } \\
\text { Purpose }\end{array}$ & $\begin{array}{l}\text { Primary } \\
\text { Responsibility } \\
\text { for Safety }\end{array}$ & $\begin{array}{l}\text { Human Is Free } \\
\text { to Engage in } \\
\text { Non-Driving } \\
\text { Related } \\
\text { Activities }\end{array}$ \\
\hline \multirow{4}{*}{ Driving } & Safety Assistance & Momentary intervention(s) & Enhanced safety & Driver & No \\
\hline & Driver Assistance & $\begin{array}{l}\text { Human and technology each } \\
\text { perform part of the driving task }\end{array}$ & $\begin{array}{l}\text { Convenience and } \\
\text { potential } \\
\text { enhanced safety }\end{array}$ & Driver & No \\
\hline & Supervised Driving & $\begin{array}{l}\text { Automated driving system that } \\
\text { requires human supervision }\end{array}$ & $\begin{array}{l}\text { Convenience and } \\
\text { potential } \\
\text { enhanced safety }\end{array}$ & Driver & No \\
\hline & $\begin{array}{l}\text { Autonomous Test } \\
\text { Vehicle }\end{array}$ & $\begin{array}{l}\text { Self-driving vehicle that requires } \\
\text { professional human supervision }\end{array}$ & Testing & Driver & No \\
\hline \multirow{2}{*}{ Riding } & $\begin{array}{l}\text { Intermittent Self- } \\
\text { Driving }\end{array}$ & $\begin{array}{l}\text { Technology performs all of the } \\
\text { driving task for a limited set of } \\
\text { use conditions }\end{array}$ & $\begin{array}{l}\text { Enhanced safety } \\
\text { and convenience }\end{array}$ & Vehicle & $\begin{array}{l}\text { Yes } \\
\text { (only when in } \\
\text { autonomous mode) }\end{array}$ \\
\hline & Driverless & $\begin{array}{l}\text { Technology performs all of the } \\
\text { driving task for entire trips }\end{array}$ & $\begin{array}{l}\text { Enhanced safety, } \\
\text { convenience and } \\
\text { mobility }\end{array}$ & Vehicle & Yes \\
\hline
\end{tabular}

A set of surveys were fielded to help understand the extent to which consumers were able to accurately interpret the proposed consumer-facing taxonomy in Table 1 relative to the 6-level SAE J3016 taxonomy. To evaluate the names associated with automation type, a range of alternate terms (see Table 2) were evaluated. Overall, we aimed to determine if consumers understand key diverging characteristics between automation types without in-depth education.

\section{METHOD}

\section{Participants}

Participants were recruited using online notices and web posts to the MIT AgeLab and New England University Transportation websites. The survey was open between July $6^{\text {th }}$ and July $31^{\text {st }}$, 2018. It was deployed three times to a unique set of individuals, once for each of the three sets of terms listed in Table 2. For the first two deployments, half of the sample received the set of SAE level of automation terms and definitions, the other half received the proposed set of terms and accompanying definitions. For the third deployment, the full sample received the proposed set of terms and accompanying definitions. Figure 1 summarizes participant deployment, return rate per term set, and demographic composition of the analyzed sample. 
Table 2. Set of terms and accompanying definitions tested in levels of automation survey

\begin{tabular}{|c|c|c|c|c|c|}
\hline Term Set 1 & Term Set 2 & Term Set 3 & Definition & SAE J3016 Term Set & Definition \\
\hline $\begin{array}{l}\text { Safety } \\
\text { Assistance }\end{array}$ & $\begin{array}{l}\text { Intervention } \\
\text { Technology }\end{array}$ & $\begin{array}{l}\text { Momentary } \\
\text { Intervention }\end{array}$ & $\begin{array}{l}\text { Technology that provides momentary } \\
\text { intervention(s) to vehicle control (e.g., } \\
\text { emergency braking) to enhance safety }\end{array}$ & $\begin{array}{l}\text { No Driving } \\
\text { Automation }\end{array}$ & $\begin{array}{l}\text { The driver performs the entire dynamic driving task, } \\
\text { even when enhanced by active safety systems. }\end{array}$ \\
\hline $\begin{array}{l}\text { Driver } \\
\text { Assistance }\end{array}$ & $\begin{array}{l}\text { Assisted } \\
\text { Driving }\end{array}$ & $\begin{array}{l}\text { Driver } \\
\text { Assistance }\end{array}$ & $\begin{array}{l}\text { The human and technology each } \\
\text { perform part of the driving task } \\
\text { (accelerating, braking, and monitoring } \\
\text { all road and vehicle conditions) to } \\
\text { increase convenience and to } \\
\text { potentially enhance safety }\end{array}$ & Driver Assistance & $\begin{array}{l}\text { Technology that performs the sustained and } \\
\text { operational design domain-specific execution of } \\
\text { either the lateral OR the longitudinal vehicle motion } \\
\text { control subtask of the dynamic driving task (but not } \\
\text { both simultaneously) with the expectation that the } \\
\text { driver performs the remainder of the dynamic driving } \\
\text { task. }\end{array}$ \\
\hline $\begin{array}{l}\text { Supervised } \\
\text { Driving }\end{array}$ & $\begin{array}{l}\text { Supervised } \\
\text { Driving }\end{array}$ & $\begin{array}{l}\text { Supervised } \\
\text { Driving }\end{array}$ & $\begin{array}{l}\text { Technology that performs all of the } \\
\text { driving tasks (accelerating, braking, and } \\
\text { monitoring all road and vehicle } \\
\text { conditions) but that requires human } \\
\text { supervision to increase convenience } \\
\text { and to potentially enhance safety }\end{array}$ & $\begin{array}{l}\text { Partial Driving } \\
\text { Automation }\end{array}$ & $\begin{array}{l}\text { Technology that performs the sustained and } \\
\text { operational design domain-specific execution of both } \\
\text { the lateral and longitudinal vehicle motion control } \\
\text { subtasks of the dynamic driving task with the } \\
\text { expectation that the driver completes the object and } \\
\text { event detection and response subtask and supervises } \\
\text { the technology. }\end{array}$ \\
\hline $\begin{array}{l}\text { Self-Driving } \\
\text { Test Vehicle }\end{array}$ & $\begin{array}{l}\text { Self-Driving } \\
\text { Test Vehicle }\end{array}$ & $\begin{array}{l}\text { Self-Driving } \\
\text { Test Vehicle }\end{array}$ & $\begin{array}{l}\text { Technology that performs all of the } \\
\text { driving task (accelerating, braking, and } \\
\text { monitoring all road and vehicle } \\
\text { conditions) but that requires } \\
\text { professional human supervision for } \\
\text { testing purposes }\end{array}$ & $\begin{array}{l}\text { Conditional Driving } \\
\text { Automation }\end{array}$ & $\begin{array}{l}\text { Technology that performs the sustained and } \\
\text { operational design domain-specific entire dynamic } \\
\text { driving task with the expectation that the dynamic } \\
\text { driving task fallback-ready user is receptive to } \\
\text { technology-issued requests to intervene, as well as to } \\
\text { dynamic driving task performance-relevant system } \\
\text { failures in other vehicle systems, and will respond } \\
\text { appropriately. }\end{array}$ \\
\hline $\begin{array}{l}\text { Intermittent } \\
\text { Self-Driving }\end{array}$ & $\begin{array}{l}\text { Conditional } \\
\text { Self-Driving }\end{array}$ & $\begin{array}{l}\text { Part-Time } \\
\text { Self-Driving }\end{array}$ & $\begin{array}{l}\text { Technology that performs all of the } \\
\text { driving task (accelerating, braking, and } \\
\text { monitoring all road and vehicle } \\
\text { conditions) for a limited set of use } \\
\text { conditions (e.g., highway only) to } \\
\text { enhance safety and convenience }\end{array}$ & $\begin{array}{l}\text { High Driving } \\
\text { Automation }\end{array}$ & $\begin{array}{l}\text { Technology that performs the sustained and } \\
\text { operational design domain-specific entire dynamic } \\
\text { driving task and dynamic driving task fallback without } \\
\text { any expectation that a user will respond to a request } \\
\text { to intervene. }\end{array}$ \\
\hline Driverless & $\begin{array}{l}\text { Full-Time Self- } \\
\text { Driving }\end{array}$ & \begin{tabular}{l|} 
\\
Autonomous \\
Driving
\end{tabular} & $\begin{array}{l}\text { Technology that performs all of the } \\
\text { driving task (accelerating, braking, and } \\
\text { monitoring all road and vehicle } \\
\text { conditions) for the entire trip to } \\
\text { enhance safety, convenience, and } \\
\text { mobility }\end{array}$ & $\begin{array}{l}\text { Full Driving } \\
\text { Automation }\end{array}$ & $\begin{array}{l}\text { Technology that performs the sustained and } \\
\text { unconditional (i.e., not operational design domain- } \\
\text { specific) entire dynamic driving task and dynamic } \\
\text { driving task fallback without any expectation that a } \\
\text { user will respond to a request to intervene. }\end{array}$ \\
\hline
\end{tabular}

In total, 292 individuals completed the survey. Responses were excluded from analysis if the respondent was not a licensed driver, did not own a vehicle, drove less than 1 day per week, had less than 5 years of driving experience, or if s/he did not complete the full survey. The age and gender breakdown for each of the three deployments per term type is summarized in Figure 1. The total sample had 181 individuals who completed the survey for the set of proposed terms and definitions, and 111 individuals who completed the survey for the comparison SAE term set and definitions; the mean age of respondents was $63(\mathrm{SD}=17)$, and $62(\mathrm{SD}=17)$, respectively. 

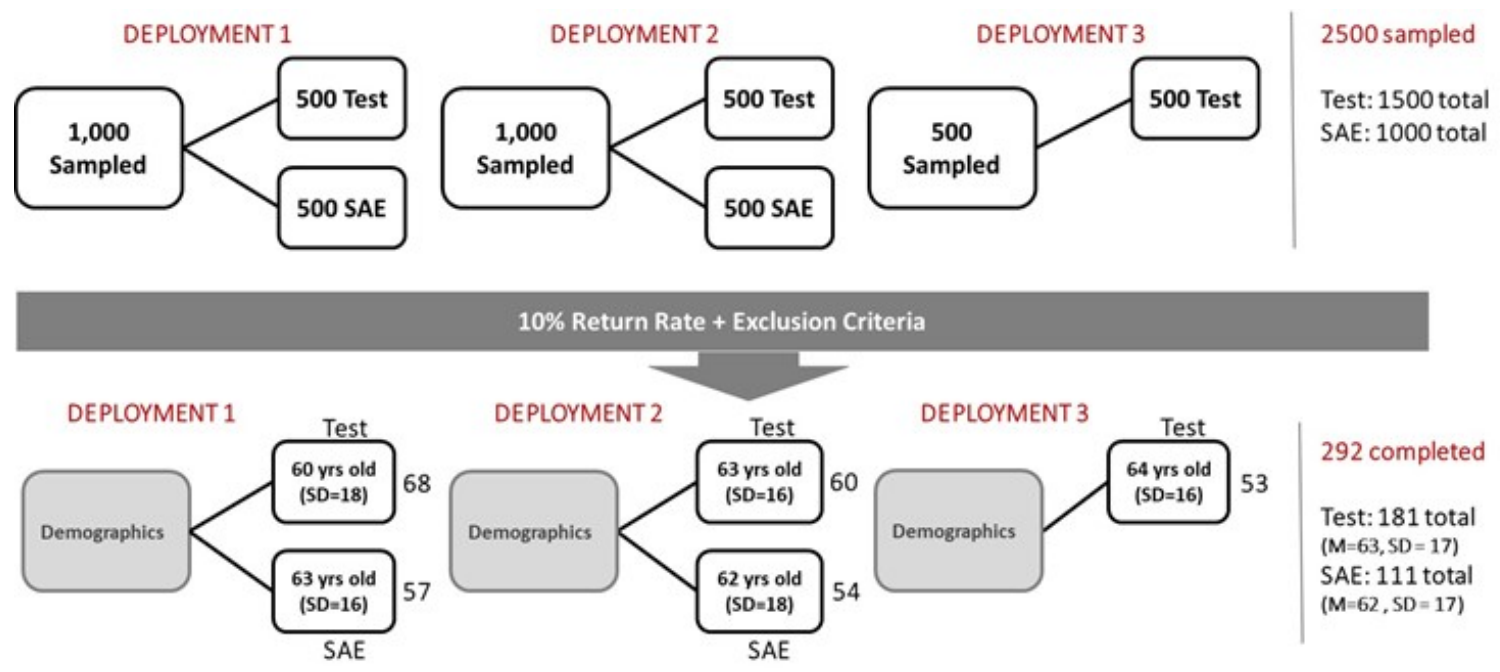

Figure 1. Participant deployment and composition showing mean age (and standard deviation).

\section{Survey procedure and instrument}

Each participant received a set of questions per automation type for the full set of six levels based on LoA taxonomy condition (MIT-proposed; SAE). The set of questions per automation type were the same, with the exception of the term and definition changing within the question's wording. Per term and definition, the following two key questions on accuracy and perceived fit, respectively, were asked:

- Question 1: Say there was a vehicle described as having technology that [Automation type

definition], on which this technology is termed [Automation type term]. From the provided definition of [Automation type term], which of the following driving tasks, if any, would you perform? (Please select all that apply)

○ Brake \& Accelerate

○ Steer

$\circ$ Monitor the Environment

$\circ$ Respond in an Emergency

- None of the Above

- Question 2: How well do you think this term [Automation term type] fits the description of the technology?

○ Not at all (1) ... Perfectly (7)

For each participant, the order in which the terms and associated definitions were administered per question set were randomized. The survey was constructed in Qualtrics and administered online.

\section{RESULTS}

Accuracy was calculated on an integer scale from $0-4$ based on a participant's selection out of four possible driving task options: 1) Brake \& Accelerate, 2) Steer, 3) Monitor the Environment, and 4) Respond in an Emergency. For each of the four options per question, participants received a " 0 " if they did not correctly select/leave blank the option, and a " 1 " if they correctly selected/left blank the option. The four integers per question were summed to produce a total score out of four. Perceived fit was assessed from the second question with the raw score from the $0-6$ Likert scale. For the set of three proposed terms, the highest average accuracy rating 
was used to select the term set for comparison with the SAE level terms. Table 3 shows the average, standard error, and $\mathrm{N}$ for each term set per automation type. For Type 2, the average of the second term had a higher score than the average of the first and third sets $(\mathrm{M}=3.41)$, which used the same term ("Driver Assistance"); the higher mean for type 2 term set 2 was selected for comparison with the SAE levels.

Table 3. Mean accuracy scores for proposed term sets
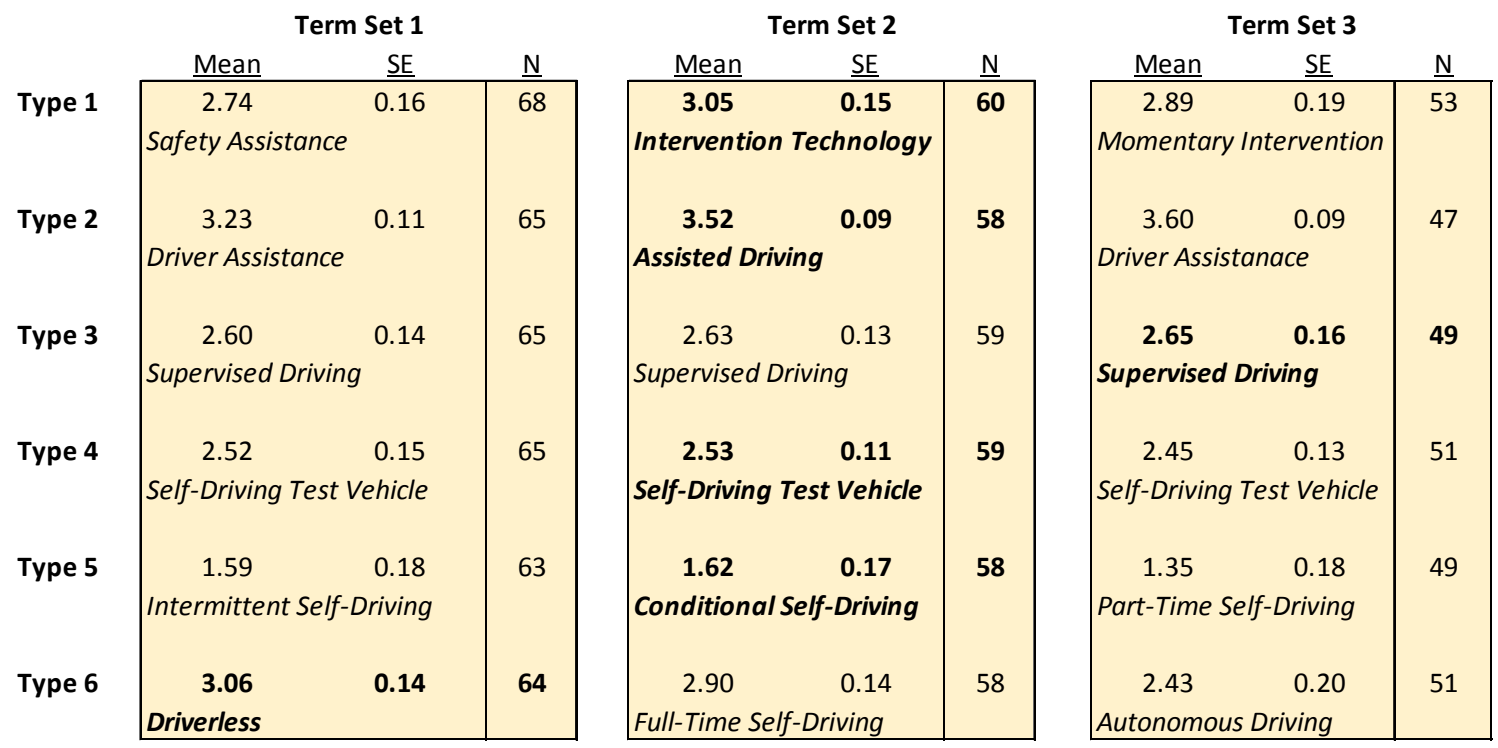

Each of the highest mean term sets was compared with the average of the scores from the SAE levels. Figure 2 shows the accuracy scores per automation type.

For Type 1, "Intervention Technology" (proposed) was significantly lower than "No Driving Automation" (SAE Level 0), $t(170)=2.62, p=.01$. For Type 2, "Assisted Driving" (proposed) was significantly higher than "Driver Assistance" (SAE Level 1); $t(163)=6.55, p<.01$. For Type 3, "Supervised Driving" (proposed) was non-significantly different than "Partial Driving Automation" (SAE Level 2), $t(153)=0.98, p=.33$. For Type 4, "Self-Driving Test Vehicle" (proposed) was significantly higher than "Conditional Driving Automation" (SAE Level 3), $t(168)=2.17, p=.03$. For Type 5, "Conditional Self-Driving" (proposed) was significantly lower than "High Driving Automation" (SAE Level 4), $t(163)=5.74, p<.001$. For Type 6, "Driverless" (proposed) was non-significantly different than "Full Driving Automation" (SAE Level 5), $t(169)=0.82, p=.41$. The same set of proposed terms that ranked highest on accuracy were used for comparison with SAE automation types on perceived fit. Figure 3 shows the perceived fit scores per automation type. 


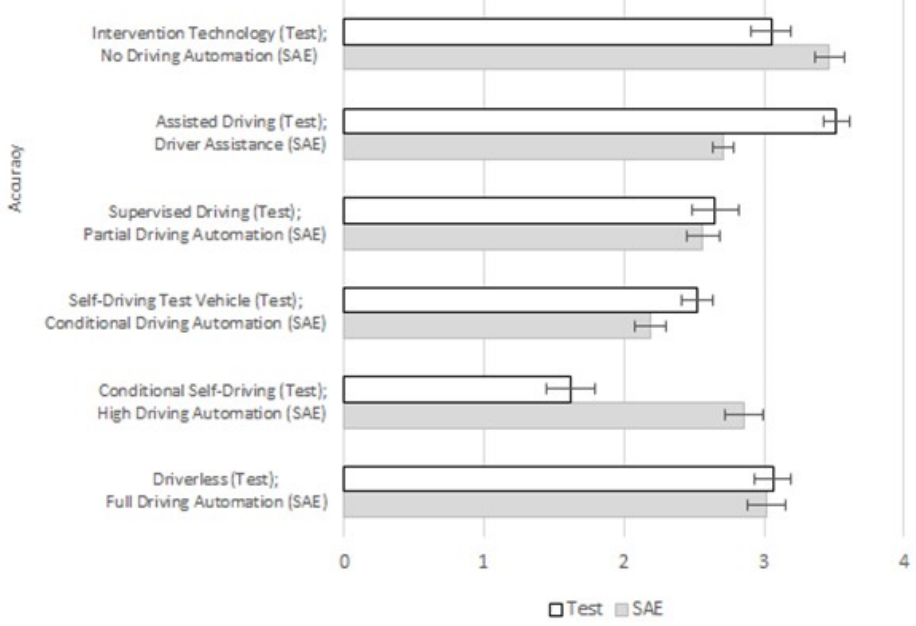

Figure 2. Comparison of highest scoring proposed and SAE automation types accuracy scores.

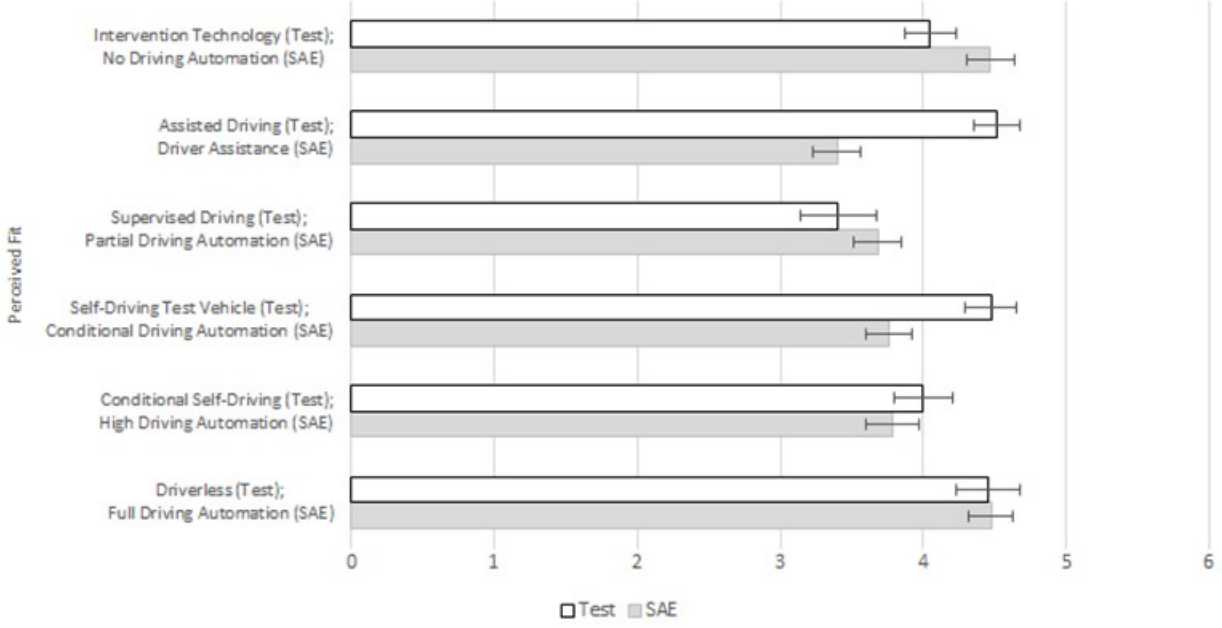

Figure 3. Comparison of highest scoring proposed and SAE automation types perceived fit scores.

For Type 1, "Intervention Technology" (proposed) was marginally lower than "No Driving Automation" (SAE Level 0), $t(170)=1.91, p=.06$. For Type 2, "Assisted Driving" (proposed) was significantly higher than "Driver Assistance" (SAE Level 1); $t(163)=4.56, p<.01$. For Type 3 , "Supervised Driving" (proposed) was non-significantly different than "Partial Driving Automation" (SAE Level 2), $t(153)=1.34, p=.18$. For Type 4, "Self-Driving Test Vehicle" (proposed) was significantly higher than "Conditional Driving Automation" (SAE Level 3), $t(161)=3.05, p<.01$. For Type 5 , "Conditional Self-Driving" (proposed) was non-significantly different than "High Driving Automation" (SAE Level 4), $t(163)=1.21, p=.23$. For Type 6, "Driverless" (proposed) was non-significantly different than "Full Driving Automation" (SAE Level 5), $t(166)=0.73, p=.47$.

\section{CONCLUSIONS}

In comparing accuracy and perceived fit between the proposed terms and the SAE terms (and their associated definitions), the results showed a mixed benefit of the proposed set over the SAE set. The proposed terms and definitions were intended to provide a clear set of driver 
responsibilities. However, varying the terms (Sets 1, 2, \& 3) for the proposed set of definitions produced only marginal benefits of increased driver accuracy in understanding those responsibilities. As compared to the SAE terms and definitions, the highest scoring proposed terms produced two significantly higher accuracy scores out of the total set of 6 . Across term types, the highest accuracy scores (above 3.0) were at the ends of the automation scale "Assisted Driving" and "Driverless" as well as "No Driving Automation". These results were mirrored with perceived fit, with the exception of "Self-Driving Test Vehicle", which also ranked high (above 4.0) among the total set of terms. This survey exercise revealed that a sample of vehicle consumers had a low to moderate (2.77) understanding of six different automation types. For both term types and definitions (proposed \& SAE), consumers were best able to differentiate the extremes of automation types, leading to the question of whether or not it may be beneficial to provide a simplified representation to communicate functionality.

Average drivers may someday possess the experience and understanding necessary to accurately consider the parsing of functionality for more complex engineering definitions of automated systems. Until it becomes a necessity to fully conceptualize automated driving systems in this way, however, a more simplistic binary framing such as "driving" and "riding" may be best suited to ensure consumer understanding. With either the new simplified dichotomy or the continued use of the 6-level SAE taxonomy, driver education around our new and evolving role as a partner with automation is a core area of need and future research.

\section{ACKNOWLEDGEMENTS}

Data were drawn from work supported by the Advanced Vehicle Technology (AVT) Consortium. The views and conclusions being expressed are those of the authors, and have not been sponsored, approved, or endorsed by the Consortium.

\section{REFERENCES}

Abraham, H., Seppelt, B., Mehler, B., \& Reimer, B. (2017). What's in a name: Vehicle technology branding \& consumer expectations for automation. In Proceedings of the $9^{\text {th }}$ International ACM Conference on Automation User Interfaces and Interactive Vehicular Applications, September 2017.

Casner, S. M., Geven, R. W., Recker, M. P., \& Schooler, J. W. (2014). The retention of manual flying skills in the automated cockpit. Human Factors, 56(8), 1506-1516.

Lee, J. D. (2018). Perspectives on Automotive Automation and Autonomy. Journal of Cognitive Engineering and Decision Making, 12(1), 53-57.

Lee, C., Seppelt, B., Mehler, B., \& Reimer, B., \& Coughlin, J. (2018). Consumer Comfort with In-Vehicle Automation: Technology of Today Drives Acceptance of a Self-Driving Future. White Paper 2018-2 - MIT AgeLab, September 2018.

SAE, Taxonomy and Definitions for Terms Related to Driving Automation Systems for OnRoad Motor Vehicles, SAE Standard J3016, USA, 2018.

Wickens, C. D., \& Kessel, C. (1981). Failure detection in dynamic systems. In Human detection and diagnosis of system failures (pp. 155-169). Springer, Boston, MA.

Woods, D. D. (2016). The risks of autonomy: Doyle's catch. Journal of Cognitive Engineering and Decision Making, 10(2), 131-133. 